\title{
Affective Ecologies: Empathy, Emotion, and Environmental Narrative. By Alexa Weik von Mossner (Columbus: Ohio State University Press, 2017), 269pp.
}

Alexandra Ganser, University of Vienna

DOI: 10.47060/jaaas.v1i1.90

In a time in which the consequences of climate change are felt locally and globally, ecocritical scholarship in the humanities is more important than ever if we want to understand what needs to be changed in the relationships between human and nonhuman environments in order to create a future of survival. The present study opens a new book series on "Cognitive Approaches to Culture" (eds. Frederick Luis Aldama, Patrick Colm Hogan, Lalita Pandit Hogan, and Sue Kim) with Ohio State University Press, which is to focus on the "social and political consequences" of cultural expression through cognitive approaches. Alexa Weik von Mossner's monograph takes up this call by studying environmental narratives across a variety of cultural production, from literary texts to film and digital culture or transmedia environments, and how these narratives crucially impact on the viewers' understanding of relations between human and nonhuman environments by involving their empathy and emotions. How different media do so is the main interest of this book.

Affective Ecologies is divided into three main parts: "Sensing Place," "Feeling with Others," and "Experiencing the Future," which follow a general introduction to the topic, in which theoretical underpinnings with regard to environmental narrative, cognitive narratology, embodiment, and emotion are discussed. Quite fittingly, the study opens with a scene from The Road, comparing its literary (2006) and filmic (2009) renditions in order to explore each version's sensory appeal as pivotal for environmental (in this case: disaster) stories, thus drawing the reader's attention skillfully to the questions the author is asking and the arguments she is presenting. Part one explores literary and filmic topophilia and creative strategies of evoking emotional ties to places by means of representation, e.g. in John Muir's classic The Mountains of California (1875). Muir's non-fictional aesthetic strategies to cognitively evoke the presence of nature on the written page are contrasted with Bonnie Nadzam's Lamb (2011), a novel which does the exact opposite, constructing nature as an absence. The comparison results in the conclusion that fiction and non-fiction are similar with regard to their potential for emotional transportation and imagined perception. In the second half of this part, Weik von Mossner explores "filmic foregrounding techniques" (73) and the affective agency of cinematic environments, such as the spectacular landscapes that Siegfried Kracauer found so intoxicating. The disaster genre, the author demonstrates, currently brings to the fore the agency of the environment (e.g. in the Hollywood movie Twister [1996]), opposing ideas of nature as passive. 
Part two centers on sustainable, empathetic relations between humans and non-humans, taking up current debates in critical animal studies. Here, the notion of strategic essentialism is taken up to understand "strategic empathy" (77) and a critical, self-reflective "strategic anthropomorphism" in the service of "trans-species empathy" (105) as it is used in literature and films such as Gorillas in the Mist (1988) and The Cove (2009) (the award-winning documentary about dolphin hunting). In this section, Weik von Mossner takes up environmental justice debates and Martha Nussbaum's discussion of the moral effects of reading literature, highlighting the importance of emotions for ideological change (98) in her discussion of two films, Thunderheart (1992) and Beasts of the Southern Wild (2012).

The third part thinks about the future alongside climate risk narratives and ecotopias (e.g. by T. C. Boyle and Kim Stanley Robinson) and the emotional power they create in the context of dystopian mourning, on the one hand, and ecotopian hope on the basis of conceptions of "ecological citizenship" (Andrew Dobson) and "eco-cosmopolitanism" (Ursula Heise), on the other. It shows how contemporary "cli-fi" balances negative and positive emotions so to keep the audience active rather than depressed (e.g. in The Day After Tomorrow [2004]) and how it personalizes the abstract-a prerogative for consciousness-raising and activism-by way of cognitive and affective strategies.

The author's readings are all excellent: sensitive and with great care for relevant yet often overlooked detail. It is laudable that she takes blockbusters and bestsellers as well as independent film equally seriously. Her argument is focused and well-structured into highly readable (sub-)chapters, presenting recent developments and insights from the cognitive sciences that lead to new and convincing interpretations of both well-known and little-explored environmental narratives. Despite the study's aim "to clarify how we interact with environmental narratives in ways that are both biologically universal and culturally specific" (back cover), what I keep wondering, however, is how readerships and their cognitive and affective viewing/reading experiences are "both biologically universal and culturally specific" exactly, and how viewers' emplacements and environmental contexts influence their cognitive and affective responses to any cultural text. The desert, as a case in point, signifies differently in the European as opposed, say, to the Arab imagination; a particular landscape, as another example, will evoke different meanings to colonized and colonizing populations. Especially in the discussion of Gorillas in the Mist, this question seems to always lurk in the background and, indeed, becomes manifest in the conflicts between Diane Fossey and the local population that Weik von Mossner mentions. How would the latter react to the film, cognitively and emotionally? The ways in which cognition, embodiment, and emotion are related to cultural background and informed by power relations remains an open question. Especially in the 


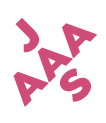

Reviews

case of the United States, ecocritical work in African American studies, e.g. by Paul Outka, and postcolonial ecocriticism could be suggestive in this regard. In the same vein, American conceptions of itself as "Nature's Nation" (Perry Miller) and related cultural myths, which keep informing America's imagined relation to the environment (as explored by David Nye and others), might have complicated the cognitive argument. Linking cognitive and contextual approaches might create new theoretical ground for future ecocritical work in literary and cultural studies. Alexa Weik von Mossner's study will certainly be an important cornerstone for such future scholarship.

\section{A Book of American Martyrs. By Joyce Carol Oates (London: Fourth Estate, 2017), 736pp.}

Johannes Mahlknecht, University of Innsbruck DOI: 10.47060/jaaas.Viil.88

With A Book of American Martyrs, Joyce Carol Oates's latest novel, the author tackles one of America's most dividing issues head-on: abortion, and with it the morality behind the opposing ideals of "pro-life" and "pro-choice." With much feeling and, it seems, no mercy, Oates pits representatives of either conviction against one another, as well as against themselves-their anger, grief, frustration, and their faith. That the novel, in its more than 700 pages, allows us to examine our own convictions-or what we think are our convictions-about the (im)morality of legalized abortion, ends up being only one of its merits.

In some detail, Oates traces the lives of two families in the aftermath of the key event that ties them together: the murder of abortion doctor Gus Voorhees and his bodyguard at the hands of the religiously motivated pro-life activist Luther Dunphy. Is it possible, the novel asks, to lament the deeds of either party (killing unborn babies vs. killing "baby killers") and yet admire both characters, Voorhees and Dunphy, not for what they did but for why they did it? For the personal sacrifices they made in order to do what they both believed to be their duty? Is it cynical to call both Vorhees and Dunphy "martyrs" (which the novel does, or appears to do), or is that exactly what they both are? Voorhees, who keeps providing abortions to desperate women despite the increasingly violent protests by religious activists, staying true to his unshakeable conviction that a woman must be granted control over her own body no matter what. And Dunphy, who knowingly risks the death penalty for his belief in defending the right to life of unborn children, even if that means destroying the life of others.

Although the plot spirals around these questions by tracing the events in the years following the murder, it is not Voorhees and Dunphy who are the protagonists 